\title{
Definitions and incidence of cardiac syndrome $X$ : review and analysis of clinical data
}

\author{
I. A. C. Vermeltfoort • P. G. H. M. Raijmakers • \\ I. I. Riphagen - D. A. M. Odekerken - A. F. M. Kuijper • \\ A. Zwijnenburg • G. J. J. Teule
}

Received: 16 July 2009/ Accepted: 7 April 2010/Published online: 21 April 2010

(C) The Author(s) 2010. This article is published with open access at Springerlink.com

\begin{abstract}
There is no consensus regarding the definition of cardiac syndrome X (CSX). We systematically reviewed recent literature using a standardized search strategy. We included 57 articles. A total of 47 studies mentioned a male/female distribution. A meta-analysis yielded a pooled proportion of females of $0.56(n=1,934$ patients, with 95\% confidence interval: 0.54-0.59). As much as 9 inclusion criteria and 43 exclusion criteria were found in the 57 articles. Applying these criteria to a population with normal coronary angiograms and treated in 1 year at a general hospital, the attributable CSX incidence varied between 3 and $11 \%$. The many inclusion and exclusion criteria result in a wide range of definitions of CSX and these have large effects on the incidence. This shows the need for a generally accepted definition of CSX.
\end{abstract}

I. A. C. Vermeltfoort ( $₫)$ · P. G. H. M. Raijmakers

Department of Nuclear Medicine and PET Research,

VU University Medical Centre, De Boelelaan 1117,

PO Box 7057, 1007 MB Amsterdam, The Netherlands

e-mail: i.vermeltfoort@vumc.nl

I. I. Riphagen

Unit for Applied Clinical Research, Medical Faculty,

Norwegian University of Science and Technology,

7491 Trondheim, Norway

D. A. M. Odekerken - A. F. M. Kuijper

Department of Cardiology, Spaarne Hospital, Spaarnepoort 1, 2134 TM Hoofddorp, The Netherlands

\section{A. Zwijnenburg}

Department of Nuclear Medicine, Spaarne Hospital,

Spaarnepoort 1, 2134 TM Hoofddorp, The Netherlands

G. J. J. Teule

Department of Nuclear Medicine, Maastricht University Medical Centre, PO Box 5800, 6202 AZ Maastricht, The Netherlands
Keywords Cardiac syndrome X · Microvascular angina . Angina pectoris and normal coronary arteries

\section{Introduction}

The syndrome of angina pectoris with a normal coronary arteriogram, often termed cardiac syndrome $\mathrm{X}$ (CSX), is an important clinical entity [65]. About $20 \%$ of patients with anginal chest pain have normal coronary angiograms (CAG). Some physicians regard this as sufficient to diagnose CSX, the so-called broad diagnosis of CSX [65, 66]. However, the cause of CSX is not conclusively established and its definition is controversial. For example, a subgroup of these patients have objective signs of ischaemia, such as the classic downsloping ST-segment depression on exercise testing and/or a reversible defect detected by myocardial single-photon emission computed tomography (SPECT). Consequently, other authorities consider that CSX is discounted by a positive result from any diagnostic test for ischaemia, especially SPECT; and there is also the view that CSX might best be relabelled as one of several causes of microvascular dysfunction [37]. Furthermore, there are various exclusion criteria, such as hypertension and diabetes, that may or may not be used to discount the diagnosis of CSX. Finally, in overviews and textbooks it is often stated that (pre-menopausal) women are especially prone to developing cardiac syndrome X. In fact, some authors exclusively study female patient populations, but there is considerable variation in the proportion of women in other studies of CSX patients.

The present paper is a review to determine the gender and main definitions for CSX in the recent literature and also the effects of different definitions upon the attributable CSX incidence. To study this latter aspect we examined 
and analysed the CAG data for a population of patients treated in a general hospital in the Netherlands.

\section{Methods}

\section{CSX definitions}

The PubMed database was used to identify papers in which criteria and definitions for CSX are described. Our search consisted of '(cardiac syndrome $x[$ tiab]) NOT (case reports[pt] OR comment[pt] OR review[pt])', with limits set to English language, humans, and publication date between June 2003 and July 2008. We limited our search strategy to cardiac syndrome $\mathrm{X}$ and excluded metabolic syndrome $X$ and tako-tsubo cardiomyopathy $[6,24,42]$.

This search yielded 112 references. Conference abstracts, pediatric papers, and 'epublications ahead of print' were excluded. Of 83 articles the full text was retrieved for further analysis. Articles were independently surveyed by two authors (IV and GT) and reviewed with regard to their used definitions of CSX. The survey left 57 studies for this review.

\section{Impact of CSX definition upon CSX incidence}

All the CAGs made in 2003 in a general hospital (Spaarne Hospital Hoofddorp, The Netherlands) were collected. An extensive search was made to obtain the clinical history, physical examination, routine laboratory tests, and echocardiography results for all patients with CAGs stated to be completely normal. All CAGs were independently evaluated by two experienced observers (AK and DO).

Only patients with original angiograms and sufficient clinical data were included in the present study.

\section{Results}

\section{CSX definitions}

The 57 papers selected for determining the main definitions of CSX covered a total of 2,375 patients. A normal coronary angiogram was used in the majority of the studies. However, in a few studies minimal coronary artery disease, like atheromatous plaque without critical obstructions, is included as "normal coronary angiogram" $[18,22,56]$. A few studies state minimal coronary artery disease in the exclusion criteria [1]. But in the majority of the studies there was no statement regarding minimal artery disease. Only few studies specified the interpretation of the normal coronary angiograms, like revision of the CAG films, blinded observation, or interpretation by more reviewers.
Table 1 lists the nine CSX definitions, and hence inclusion criteria, obtained from our review of the 57 studies.

In more detail:

- Out of the 57 studies 42 required positive exercise electrocardiograms for the diagnosis of CSX. The general criterion, when given, for a positive exercise stress test result was uniform ST depression $\geq 1 \mathrm{~mm}$. Only one study considered stress-induced angina without significant ST depression to be positive for ischaemia [15].

- As much as 11 studies regarded positive myocardial perfusion images to be good alternatives to a positive result from exercise testing.

- As much as 18 studies considered effort-induced angina pectoris as an inclusion criterion.

- Four studies defined CSX simply as angina pectoris and normal CAG, the so-called broad diagnosis of CSX.

Table 1 Inclusion criteria for CSX

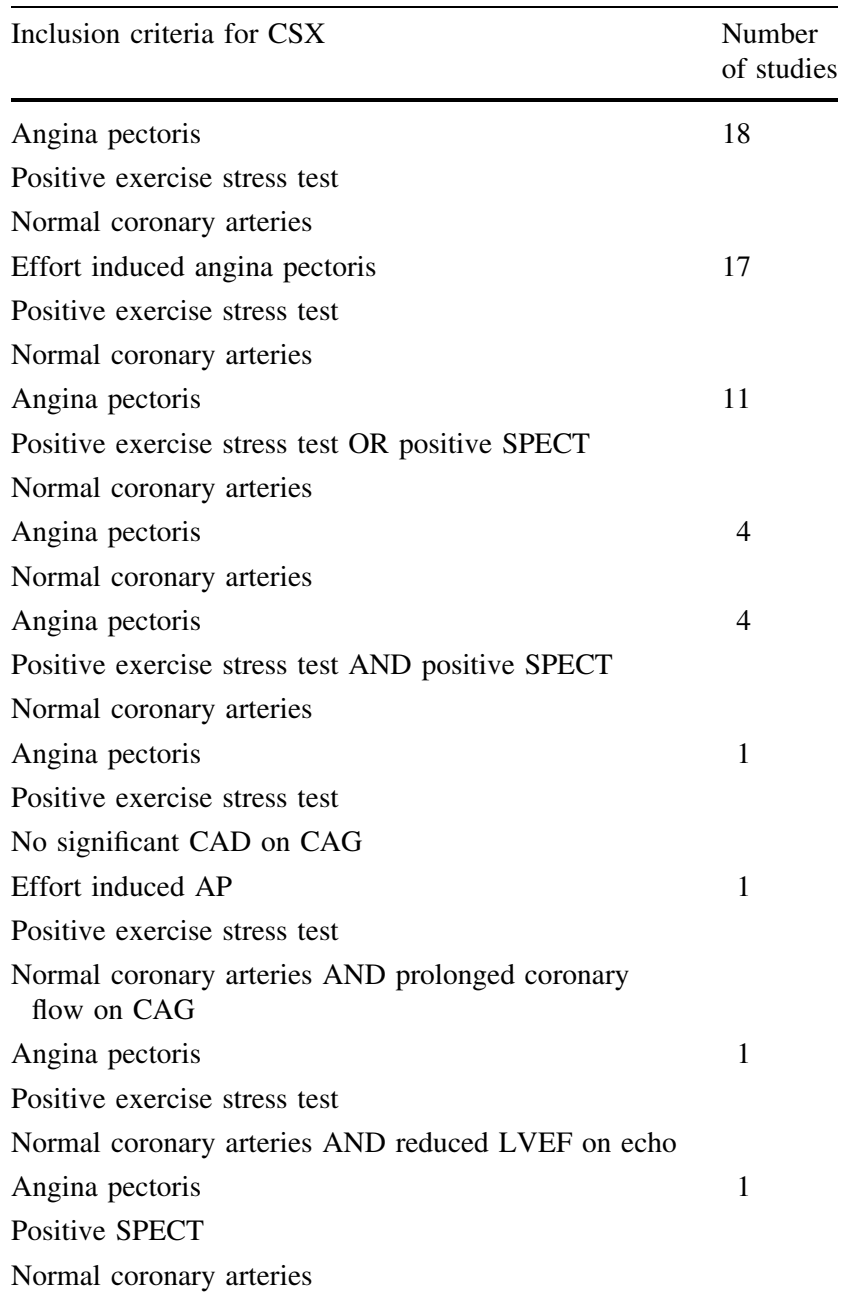

$C S X$ cardiac syndrome $\mathrm{X} ; A P$ angina pectoris; $C A G$ coronary angiogram; SPECT single photon emission tomography; $L V E F$ left ventricular ejection fraction 
Table 2 lists no less than 43 exclusion criteria for CSX. The most frequently used exclusion criteria are valvular heart disease, diabetes mellitus, left ventricular hypertrophy, hypertension, and cardiomyopathy.

Table 2 Exclusion criteria included studies

\begin{tabular}{|c|c|}
\hline $\begin{array}{l}\text { Exclusion criteria used in the studies for present } \\
\text { review }\end{array}$ & $\begin{array}{l}N \text { studies of } 57 \\
\text { total }\end{array}$ \\
\hline Valvular heart disease & 33 \\
\hline Diabetes mellitus & 32 \\
\hline Left ventricular hypertrophy & 26 \\
\hline Hypertension & 24 \\
\hline Cardiomyopathy (non specified) & 23 \\
\hline Renal failure & 22 \\
\hline History of myocardial infarction & 15 \\
\hline LV dysfunction & 14 \\
\hline Coronary spasm & 13 \\
\hline Hepatic dysfunction & 12 \\
\hline Arrhytmias & 9 \\
\hline Inflammatory disease & 9 \\
\hline Dyslipidaemia & 8 \\
\hline Left bundel branch block & 8 \\
\hline Cardiac disease (non specified) & 7 \\
\hline Gastro Intestinal disorder & 7 \\
\hline Systemic disease (non specified) & 6 \\
\hline Smoking & 6 \\
\hline Thyroid dysfunction & 5 \\
\hline Obesitas & 5 \\
\hline Non-cardiac chest pain & 5 \\
\hline Condunction disorder (incl LBTB) & $5(13)$ \\
\hline Hypertrophic CMP (total CMP) & $5(23)$ \\
\hline Congestive CMP (total CMP) & $5(23)$ \\
\hline Dilated CMP (CMP total) & $4(23)$ \\
\hline Alcoholism & 4 \\
\hline Metabolic syndrome & 4 \\
\hline Dysphagia/oesophagitis & 3 \\
\hline Malignancy & 3 \\
\hline $\mathrm{LVEF}<40 \%$ & 2 \\
\hline Psychiatric ilness & 2 \\
\hline Auto immune disease & 2 \\
\hline Estrogen replacement therapy & 2 \\
\hline PTCA/CABG in history & 2 \\
\hline Ectasia on CAG & 2 \\
\hline Bridging on $\mathrm{CAG}$ & 2 \\
\hline Claudicatio intermittens & 2 \\
\hline Heart failure (non specfied) (total) & $1(17)$ \\
\hline Myocarditis & 1 \\
\hline Congenital heart disease & 1 \\
\hline Aortic wall diseases & 1 \\
\hline Anaemia & 1 \\
\hline Thrombocytopenia & 1 \\
\hline
\end{tabular}

In overviews and textbooks it is often stated that (premenopausal) women are especially prone to develop cardiac syndrome $\mathrm{X}$.

In Table 3 data of individual studies are presented.

Table 3 Included studies of CSX patients

\begin{tabular}{|c|c|c|c|c|}
\hline $\begin{array}{l}\text { Included study } \\
\text { of CSX patients }\end{array}$ & Year & $n$ & $\begin{array}{l}\text { Female } \\
(\%)\end{array}$ & $\begin{array}{l}\text { Mean } \\
\text { age (Y) }\end{array}$ \\
\hline Lee [41] & 2008 & 21 & 81 & 55 \\
\hline Timurkaynak [61] & 2008 & 79 & 54 & 50 \\
\hline Cemin [11] & 2008 & 11 & 100 & 59 \\
\hline Zorc-Pleskovic [66] & 2008 & 31 & 100 & 55 \\
\hline Lanza [38] & 2008 & 18 & 61 & 58 \\
\hline Altun [2] & 2007 & 9 & 77 & 49 \\
\hline Cotrim [12] & 2008 & 91 & 48 & 51 \\
\hline Asbury [5] & 2008 & 64 & 100 & 58 \\
\hline Demir [18] & 2008 & 17 & 41 & 57 \\
\hline Grabczewska [23] & 2007 & 53 & 57 & 55 \\
\hline Li [44] & 2007 & 36 & 100 & NA \\
\hline Okyay [48] & 2007 & 32 & 66 & 53 \\
\hline Dabek [15] & 2007 & 34 & 65 & 57 \\
\hline Yildiz [64] & 2007 & 10 & 79 & 49 \\
\hline Kayikcioglu [33] & 2007 & 30 & 60 & 46 \\
\hline Mao [45] & 2007 & 51 & 78 & 21 \\
\hline Dabek [14] & 2007 & 36 & 65 & 57 \\
\hline Vermeltfoort [63] & 2007 & 20 & 75 & 55 \\
\hline Galiuto [21] & 2007 & 17 & 53 & 55 \\
\hline Alroy [1] & 2007 & 42 & 100 & 52 \\
\hline Huang [29] & 2007 & 12 & 60 & 63 \\
\hline Guzik [28] & 2007 & 43 & 65 & 44 \\
\hline Gur [26] & 2007 & 23 & 70 & 49 \\
\hline Gur [27] & 2007 & 23 & NA & NA \\
\hline Sgueglia [59] & 2007 & 30 & 73 & 61 \\
\hline Russell [55] & 2007 & 24 & 89 & 54 \\
\hline Sen [56] & 2007 & 203 & 58 & 53 \\
\hline Shmilovich [60] & 2007 & 17 & 71 & 58 \\
\hline de Vries [17] & 2006 & 42 & 26 & 58 \\
\hline Nam [47] & 2006 & 52 & NA & NA \\
\hline Eskandarian [19] & 2006 & 40 & 73 & 46 \\
\hline Cay [10] & 2006 & 126 & 62 & 53 \\
\hline Jadhav [30] & 2006 & 52 & 100 & 56 \\
\hline Czepczynski [13] & 2006 & 68 & 63 & 45 \\
\hline Leu [43] & 2006 & 92 & 21 & 64 \\
\hline Lanza [40] & 2005 & 10 & 59 & 70 \\
\hline Cay [9] & 2005 & 80 & 52 & 51 \\
\hline On [49] & 2005 & 36 & 53 & 36 \\
\hline Guo [25] & 2005 & 22 & 68 & 48 \\
\hline Masci [46] & 2005 & 41 & NA & 53 \\
\hline Senen [57] & 2005 & 21 & 48 & 56 \\
\hline Pasqui [51] & 2005 & 30 & 60 & 54 \\
\hline Sestito [58] & 2005 & 30 & 73 & 60 \\
\hline
\end{tabular}


Table 3 continued

\begin{tabular}{lllll}
\hline $\begin{array}{l}\text { Included study } \\
\text { of CSX patients }\end{array}$ & Year & $n$ & $\begin{array}{l}\text { Female } \\
(\%)\end{array}$ & $\begin{array}{l}\text { Mean } \\
\text { age (Y) }\end{array}$ \\
\hline De Candia [16] & 2005 & 21 & 57 & 55 \\
Valeriani [62] & 2005 & 16 & 50 & 60 \\
Cavusoglu [8] & 2005 & 31 & 45 & 52 \\
Kolasinska-Kloch [36] & 2004 & 42 & 52 & 46 \\
Kolasilska-Kloch [35] & 2004 & 25 & 36 & 49 \\
Altun [3] & 2004 & 8 & 75 & 46 \\
Asbury [4] & 2004 & 100 & 100 & 61 \\
Fabian [20] & 2004 & 40 & 40 & 55 \\
Lanza [39] & 2004 & 55 & 50 & 57 \\
Qian [54] & 2004 & 126 & 47 & 53 \\
Osamichi [50] & 2004 & 24 & 71 & 58 \\
Gorgulu [22] & 2003 & 18 & 44 & 51 \\
Pizzi [53] & 2004 & NA & NA & 59 \\
Kidawa [34] & 2003 & 50 & 64 & 49 \\
\hline
\end{tabular}

NA not available

In 53 out of the total of 57 included studies the female/ male distribution of the study population was mentioned. Six studies were focussed upon female patients with CSX. These studies were excluded for the pooling of the proportion of women in the study populations. Ultimately 47 studies with a total of 1,934 patients could be used for the meta-analysis.

The proportion of women in the 47 studies of CSX patients varied considerably ranging from 0.21 to 1.0 , with a pooled estimate of 0.56 (95\% confidence interval: 0.54 0.59), see also Fig. 1. Hence, there is a significantly higher proportion of woman compared to males in the group of patients with CSX.

\section{CSX incidence}

As much as 567 CAGs were performed in 1 year at a general hospital. Figure 2 is a flowchart showing how we analysed the available information. The main stages are:

- Original CAGs or clinical data could not be found for eight patients, leaving 559 cases for analysis.

- Out of the available 559 CAGs 78 (14\%) were considered as absolutely normal.

- Excluding 13 cases with no angina pectoris as indication for $\mathrm{CAG}$, and another 5 with an acute coronary syndrome, resulted in an incidence of 60 (11\%) CSX patients according to the broad diagnosis of CSX (angina pectoris and normal coronary arteries) [17, 23, 54, 65, 66].

- Another 15 cases were excluded owing to the lack of exercise stress tests or myocardial perfusion imaging preceding the CAG.

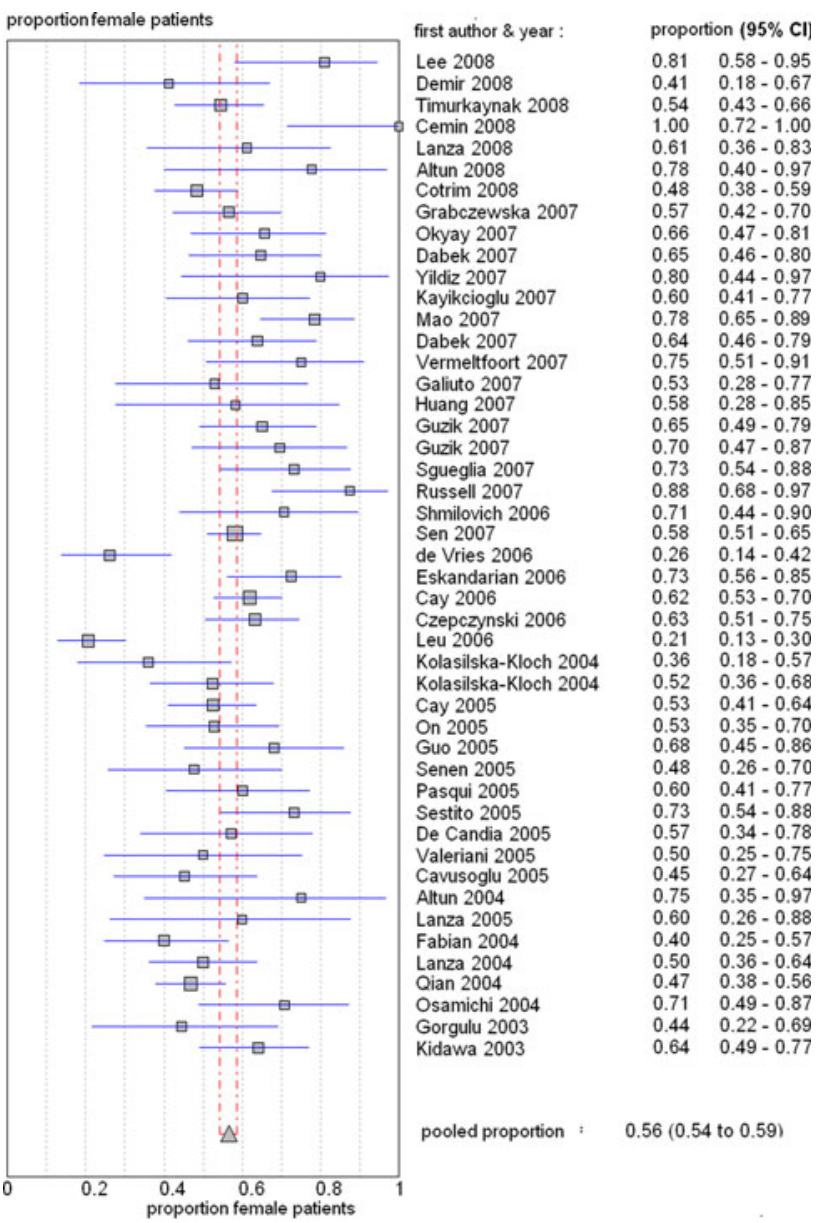

Fig. 1 Plot of proportion of women of individual studies, including 95\% confidence intervals

- Of the remaining 45 cases, 28 were included owing to positive results for ischaemia from exercise tests or SPECT.

- Finally, a much stricter definition of CSX was obtained by using the main exclusion criteria shown in the second-to-last stage in Fig. 2. This strict definition resulted in an attributable CSX incidence of 18 (3\%) patients.

\section{Discussion}

CSX definitions and incidences

The present review of recent archival literature demonstrates that there is a wide range of definitions of CSX. This wide range of definitions has a large effect on the attributable incidence of CSX, as has been shown by an analysis of all available CAGs and other clinical data for a population of patients treated in 1 year at a general hospital. 


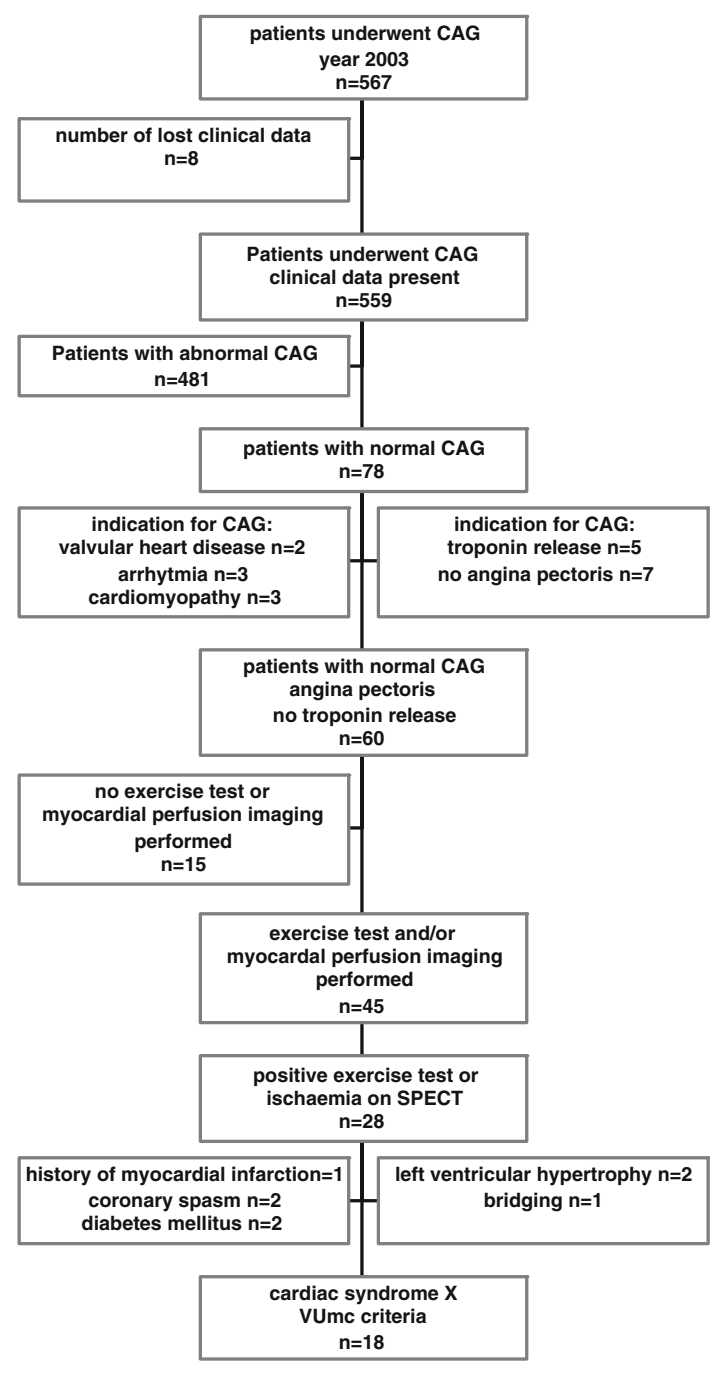

Fig. 2 Flowchart of the available information

Generally, it is stated that patients with chest pain and normal coronary arteriogram may represent $10-20 \%$ of those undergoing coronary arteriography because of clinical suspicion of angina [65]. This is in broad agreement with our analysis results that $11 \%$ of patients had a normal CAG. The rather low incidence of normal CAG can be the result of the use of rather strict criteria for a normal CAG including a consensus reading by two independent readers of the CAG's.

It is generally accepted (e.g. in authoritative textbooks) that the majority of the CSX patients are women [32, 65]. Some authors have even suggested that CSX is a women's disease. However, our review has found a pooled relative female frequency of $56 \%$ in a population of more than 1,900 CSX patients. Thus, our data do not support the assumption that CSX is a women's disease, since $44 \%$ of the population was male. Potential pathophysiological explanations, such as estrogen depletion, which are based upon the female gender, apply only to a part of the CSX patients [31].

Inclusion and exclusion criteria

The literature survey showed that the inclusion and exclusion criteria varied. This was especially the case for the exclusion criteria.

The definition of 'normal coronary arteries' was particularly unclear. Most studies did not define a normal CAG, and some included patients with coronary artery disease (CAD) ranging from minimal to stenoses up to $50 \%$ of luminal diameter. Obviously, normal coronary arteries are the cornerstone of the diagnosis of CSX. Hence, there should be no doubt regarding the use of this inclusion criterion for studies of CSX patients. Future studies of CSX patients should make a clear description regarding the evaluation and results of the CAG studies of the coronary artery anatomy.

The so-called broad diagnosis for CSX, a combination of 2 inclusion criteria (angina pectoris and normal coronary arteries) was used only in four studies (7\%).

Most studies used a combination of three inclusion criteria, namely (effort induced) angina pectoris, positive exercise test result, and a normal CAG. This definition was used in 46 out of 57 studies (81\%). The use of this additional inclusion criterion resulted in a decrease of the incidence of CSX to 7\% in our population. The definition of a positive exercise stress test appears to be more standardized than the definition of a normal CAG. Most publications used a ST depression $\geq 1 \mathrm{~mm}$ as a positive exercise stress test: only 12 out of the 57 studies did not define a positive stress test.

The use of specific exclusion criteria ranged from 2 to $58 \%$ of the selected studies of CSX patients, often depending on the main objectives of the studies, for example the use of thrombocytopenia as an exclusion criterion in a study investigating the mean platelet volume [9].

The most frequently mentioned exclusion criteria are valvular heart disease, diabetes mellitus, left ventricular hypertrophy, hypertension, and cardiomyopathy. Endothelial dysfunction has been assessed both in patients with diabetes mellitus and hypertension with normal CAG, and in patients with CSX without diabetes or hypertension. Interestingly, coronary flow reserve may be reversible in specific patient groups, e.g. in patients with hypertrophy after anti-hypertensive therapy [52]. However, we note that most international studies consider diabetes mellitus and hypertension to be exclusion criteria for CSX, thereby considering these patients as a separate group.

The existence of such a long list of exclusion criteria in the selection process of CSX patients illustrates the lack of agreement between the different research groups regarding 
the origins of this syndrome. Besides the use of a standard and fixed combination of inclusion criteria future studies should apply a standard combination of exclusion criteria.

In a recent editorial, Camici proposed the following exclusion criteria in order to obtain a more homogeneous set of cardiac syndrome X patients: absence of left bundle branch block; absence of even minimal irregularities on the angiogram; no evidence of diabetes mellitus, arterial hypertension, hyperlipidaemia, valve disease, epicardial arterial spasm, and cardiomyopathy [7].

In our selection of CSX patients we decided to include only patients with completely normal coronary angiograms, effort-induced angina pectoris, positive exercise stress test and/or positive SPECT study. Furthermore, we decided to add arrhythmias, left ventricular hypertrophy, myocardial infarction in the medical history, and myocardial bridging to the exclusion criteria proposed by Camici. These inclusion and exclusion criteria resulted in an attributable CSX incidence of only 3\%.

\section{Conclusions}

The wide range of definitions of CSX in recent literature and the variations in inclusion and exclusion criteria, particularly the latter, make interpretation of the results of individual studies difficult. This shows the need for a generally accepted definition of CSX.

Acknowledgments We thank Dr. R.J.H. Wanhill for his critical review and editing of the manuscript.

\section{Conflict of interest statement None.}

Open Access This article is distributed under the terms of the Creative Commons Attribution Noncommercial License which permits any noncommercial use, distribution, and reproduction in any medium, provided the original author(s) and source are credited.

\section{References}

1. Alroy S, Preis M, Barzilai M et al (2007) Endothelial cell dysfunction in women with cardiac syndrome $X$ and MTHFR C677T mutation. Isr Med Assoc J 9:321-325

2. Altun A, Turgut N, Tatli E et al (2007) Sympathetic skin response and RR interval variation in patients with cardiac syndrome $\mathrm{X}$. Angiology 58:747-750

3. Altun A, Ugur-Altun B, Tatli E (2004) Decreased serum osteoprotegerin levels in patients with cardiac syndrome X. J Endocrinol Invest 27:839-843

4. Asbury EA, Creed F, Collins P (2004) Distinct psychosocial differences between women with coronary heart disease and cardiac syndrome X. Eur Heart J 25:1695-1701

5. Asbury EA, Slattery C, Grant A et al (2008) Cardiac rehabilitation for the treatment of women with chest pain and normal coronary arteries. Menopause 15:454-460
6. Athanasiadis A, Vogelsberg H, Hauer B et al (2006) Transient left ventricular dysfunction with apical ballooning (tako-tsubo cardiomyopathy) in Germany. Clin Res Cardiol 95:321-328

7. Camici PG (2007) Is the chest pain in cardiac syndrome $X$ due to subendocardial ischaemia? Eur Heart J 28:1539-1540

8. Cavusoglu Y, Entok E, Timuralp B et al (2005) Regional distribution and extent of perfusion abnormalities, and the lung to heart uptake ratios during exercise thallium-201 SPECT imaging in patients with cardiac syndrome X. Can J Cardiol 21:57-62

9. Cay S, Biyikoglu F, Cihan G et al (2005) Mean platelet volume in the patients with cardiac syndrome X. J Thromb Thrombolysis 20:175-178

10. Cay S, Guray U, Korkmaz S (2006) Increased aortic pulse and fractional pulse pressures in patients with cardiac syndrome X. Blood Press 15:179-184

11. Cemin R, Erlicher A, Fattor B et al (2008) Reduced coronary flow reserve and parasympathetic dysfunction in patients with cardiovascular syndrome X. Coron Artery Dis 19:1-7

12. Cotrim C, Almeida AG, Carrageta M (2008) Exercise-induced intra-ventricular gradients as a frequent potential cause of myocardial ischemia in cardiac syndrome $\mathrm{X}$ patients. Cardiovasc Ultrasound 6:3

13. Czepczynski R, Smolarek I, Rogacka D et al (2006) Myocardial perfusion SPECT with dipyridamole stress test in cardiac syndrome X. Nuklearmedizin 45:111-114

14. Dabek J, Kulach A, Wilczok T et al (2007) Transcriptional activity of genes encoding interferon gamma (IFNgamma) and its receptor assessed in peripheral blood mononuclear cells in patients with cardiac syndrome X. Inflammation 30:125-129

15. Dabek J, Wilczok T, Gasior Z et al (2007) Gene expression of kinin receptors B1 and B2 in PBMC from patients with cardiac syndrome X. Scand Cardiovasc J 41:391-396

16. De Candia E, Lanza GA, Romagnoli E et al (2005) Abnormal pH-sensing of platelet $\mathrm{Na}+\mathrm{H}+$ exchanger in patients with cardiac syndrome X. Int J Cardiol 100:371-376

17. de Vries J, DeJongste MJ, Jessurun GA et al (2006) Myocardial perfusion quantification in patients suspected of cardiac syndrome $\mathrm{X}$ with positive and negative exercise testing: a [13N]ammonia positron emission tomography study. Nucl Med Commun 27:791-794

18. Demir H, Kahraman G, Isgoren S et al (2008) Evaluation of poststress left ventricular dysfunction and its relationship with perfusion abnormalities using gated SPECT in patients with cardiac syndrome X. Nucl Med Commun 29:208-214

19. Eskandarian R, Malek M, Mousavi SH et al (2006) Association of Helicobacter pylori infection with cardiac syndrome X. Singapore Med J 47:704-706

20. Fabian E, Varga A, Picano E et al (2004) Effect of simvastatin on endothelial function in cardiac syndrome $\mathrm{X}$ patients. Am J Cardiol 94:652-655

21. Galiuto L, Sestito A, Barchetta S et al (2007) Noninvasive evaluation of flow reserve in the left anterior descending coronary artery in patients with cardiac syndrome X. Am J Cardiol 99:1378-1383

22. Gorgulu S, Uslu N, Eren M et al (2003) Aortic stiffness in patients with cardiac syndrome X. Acta Cardiol 58:507-511

23. Grabczewska Z, Thews M, Goralczyk K et al (2007) Endothelial function in patients with chest pain and normal coronary angiograms. Kardiol Pol 65:1199-1206

24. Grawe H, Katoh M, Kuhl HP (2006) Stress cardiomyopathy mimicking acute coronary syndrome: case presentation and review of the literature. Clin Res Cardiol 95:179-185

25. Guo H, Lee JD, Guo M et al (2005) Status of intracellular and extracellular magnesium concentration in patients with cardiac syndrome X. Acta Cardiol 60:259-263

26. Gur M, Yildiz A, Demirbag R et al (2007) Paraoxonase and arylesterase activities in patients with cardiac syndrome $\mathrm{X}$, and 
their relationship with oxidative stress markers. Coron Artery Dis 18:89-95

27. Gur M, Yildiz A, Demirbag R et al (2007) Increased lymphocyte deoxyribonucleic acid damage in patients with cardiac syndrome X. Mutat Res 617:8-15

28. Guzik P, Rogacka D, Trachalski J et al (2007) Comparison of the exercise treadmill test and 24-hour ECG Holter monitoring in patients with syndrome $\mathrm{X}$ or coronary atherosclerosis. Kardiol Pol 65:262-269

29. Huang PH, Chen YH, Chen YL et al (2007) Vascular endothelial function and circulating endothelial progenitor cells in patients with cardiac syndrome X. Heart 93:1064-1070

30. Jadhav ST, Ferrell WR, Petrie JR et al (2006) Microvascular function, metabolic syndrome, and novel risk factor status in women with cardiac syndrome X. Am J Cardiol 97:1727-1731

31. Kaski JC (2006) Cardiac syndrome $X$ in women: the role of oestrogen deficiency. Heart 92(Suppl 3):iii5-iii9

32. Kaski JC (2002) Overview of gender aspects of cardiac syndrome X. Cardiovasc Res 53:620-626

33. Kayikcioglu M, Saygi S, Azarsiz E et al (2007) Serum paraoxonase 1 activity and oxidative markers of LDL in patients with cardiac syndrome X. Acta Cardiol 62:245-249

34. Kidawa M, Krzeminska-Pakula M, Peruga JZ et al (2003) Cardiological syndrome X Non-invasive assessment of endothelial function and arterial compliance. Kardiol Pol 59:385-396

35. Kolasilska-Kloch W, Lesniak W, Leszczynska-Golabek I et al (2004) Exercise tolerance and hyperinsulinemia in cardiac syndrome X. Folia Med Cracov 45:13-23

36. Kolasinska-Kloch W, Furgala A, Krolczyk G et al (2004) Cardiac syndrome X-autonomic system disorders. Folia Med Cracov 45:19-29

37. Lanza GA (2007) Cardiac syndrome X: a critical overview and future perspectives. Heart 93:159-166

38. Lanza GA, Buffon A, Sestito A et al (2008) Relation between stress-induced myocardial perfusion defects on cardiovascular magnetic resonance and coronary microvascular dysfunction in patients with cardiac syndrome X. J Am Coll Cardiol 51:466-472

39. Lanza GA, Sestito A, Cammarota G et al (2004) Assessment of systemic inflammation and infective pathogen burden in patients with cardiac syndrome X. Am J Cardiol 94:40-44

40. Lanza GA, Sestito A, Sgueglia GA et al (2005) Effect of spinal cord stimulation on spontaneous and stress-induced angina and 'ischemia-like' ST-segment depression in patients with cardiac syndrome X. Eur Heart J 26:983-989

41. Lee BK, Durairaj A, Mehra A et al (2008) Microcirculatory dysfunction in cardiac syndrome $\mathrm{X}$ : role of abnormal blood rheology. Microcirculation 15:451-459

42. Leichman JG, Lavis VR, Aguilar D et al (2006) The metabolic syndrome and the heart-a considered opinion. Clin Res Cardiol 95(Suppl 1):i134-i141

43. Leu HB, Lin CP, Lin WT et al (2006) Circulating mononuclear superoxide production and inflammatory markers for long-term prognosis in patients with cardiac syndrome X. Free Radic Biol Med 40:983-991

44. Li JJ, Zhu CG, Nan JL et al (2007) Elevated circulating inflammatory markers in female patients with cardiac syndrome $\mathrm{X}$. Cytokine 40:172-176

45. Mao JY, Ge YB, Wang HH et al (2007) Summary of 32 patients with cardiac syndrome $\mathrm{X}$ treated by TCM therapy of regulating qi relieving chest stuffiness and promoting blood circulation. Chin J Integr Med 13:17-21

46. Masci PG, Laclaustra M, Lara JG et al (2005) Brachial artery flow-mediated dilation and myocardial perfusion in patients with cardiac syndrome X. Am J Cardiol 95:1478-1480
47. Nam CW, Kim KS, Lee YS et al (2006) The incidence of gastroesophageal disease for the patients with typical chest pain and a normal coronary angiogram. Korean J Intern Med 21:94-96

48. Okyay K, Cengel A, Sahinarslan A et al (2007) Plasma asymmetric dimethylarginine and L-arginine levels in patients with cardiac syndrome X. Coron Artery Dis 18:539-544

49. On YK, Park R, Hyon MS et al (2005) Are low total serum antioxidant status and elevated levels of C-reactive protein and monocyte chemotactic protein-1 associated with cardiac syndrome X? Circ J 69:1212-1217

50. Osamichi S, Kouji K, Yoshimaro I et al (2004) Myocardial glucose metabolism assessed by positron emission tomography and the histopathologic findings of microvessels in syndrome X. Circ J 68:220-226

51. Pasqui AL, Puccetti L, Di Renzo M et al (2005) Structural and functional abnormality of systemic microvessels in cardiac syndrome X. Nutr Metab Cardiovasc Dis 15:56-64

52. Petkow Dimitrow P, Krzanowski M, Nizankowski R et al (2000) Effect of verapamil on systolic and diastolic coronary blood flow velocity in asymptomatic and mildly symptomatic patients with hypertrophic cardiomyopathy. Heart 83:262-266

53. Pizzi C, Manfrini O, Fontana F et al (2004) Angiotensin-converting enzyme inhibitors and 3-hydroxy-3-methylglutaryl coenzyme A reductase in cardiac Syndrome X: role of superoxide dismutase activity. Circulation 109:53-58

54. Qian JY, Ge JB, Fan B et al (2004) Identification of syndrome X using intravascular ultrasound imaging and Doppler flow mapping. Chin Med J (Engl) 117:521-527

55. Russell SJ, Di Stefano EM, Naffati MT et al (2007) The effects of the angiotensin II receptor (type I) antagonist irbesartan in patients with cardiac syndrome X. Heart 93:253-254

56. Sen N, Tavil Y, Yazici HU et al (2007) Coronary blood flow in patients with cardiac syndrome X. Coron Artery Dis 18:45-48

57. Senen K, Ileri M, Alper A et al (2005) Increased levels of soluble adhesion molecules E-selectin and P-selectin in patients with cardiac syndrome X. Angiology 56:273-277

58. Sestito A, Maccallini A, Sgueglia GA et al (2005) Platelet reactivity in response to mental stress in syndrome $X$ and in stable or unstable coronary artery disease. Thromb Res 116:25-31

59. Sgueglia GA, Sestito A, Spinelli A et al (2007) Long-term follow-up of patients with cardiac syndrome $\mathrm{X}$ treated by spinal cord stimulation. Heart 93:591-597

60. Shmilovich H, Deutsch V, Roth A et al (2007) Circulating endothelial progenitor cells in patients with cardiac syndrome $\mathrm{X}$. Heart 93:1071-1076

61. Timurkaynak T, Balcioglu S, Arslan U et al (2008) Plasma homocysteine level in cardiac syndrome $\mathrm{X}$ and its relation with duke treadmill score. Saudi Med J 29:364-367

62. Valeriani M, Sestito A, Le Pera D et al (2005) Abnormal cortical pain processing in patients with cardiac syndrome X. Eur Heart J 26:975-982

63. Vermeltfoort IA, Bondarenko O, Raijmakers PG et al (2007) Is subendocardial ischaemia present in patients with chest pain and normal coronary angiograms? A cardiovascular MR study. Eur Heart J 28:1554-1558

64. Yildiz M, Altun A, Ozbay G (2007) Assessment of arterial distensibility in patients with cardiac syndrome X. Angiology 58:458-462

65. Zipes DP, Libby P, Bonow RO et al (2008) Braunwald's heart disease: a textbook of cardiovascular medicine, 8 edn. SaundersElsevier, Philadelphia

66. Zorc-Pleskovic R, Vraspir-Porenta O, Zorc M et al (2008) Inflammatory changes in small blood vessels in the endomyocardium of cardiac syndrome $\mathrm{X}$ in female patients with increased C-reactive protein. Folia Biol (Praha) 54:30-32 